NBER WORKING PAPER SERIES

SOCIAL SECURITY AND THE DECISION TO RETIRE

Anthony J. Pellechio

Working Paper No. $73 \underline{4}$

NATIONAL BUREAU OF ECONOMIC RESEARCH 1050 Massachusetts Av enue

Cambridge MA 02138

August 1981

Assistant Professor of Economics, University of Rochester. I want to thank Catherine Helbig for her assistance with this research. The research reported here is part of the NBER's research program on Social Insurance. Any opinions expressed are those of the author and not those of the National Bureau of Economic. Research. 
Social Security and the Decision to Retire

\section{ABSTRACT}

This study examines empirically whether social security influences the retirement decisions of individuals. The framework for this study is the life-cycle model of individual behavior. The life-cycle model shows that there are two main ways in which social security can affect behavior. One way is through the change in an individual's lifetime income that social security can bring about. The other way has to do with how the system changes compensation for work. Social security's income and substitution effects are included in a model for examining retirement decisions. This model is based on the model of labor force participation that has become standard in the literature on labor supply. The data used in this study come from the Social Security Administration and are particularly well suited for this study. Retirement models are estimated separately for samples of 62-64 and 65-70 year old men. The empirical results support the conclusion that social security influences the decision to retire. The magnitude of behavioral responses to changes in social security benefits are reported and implications for future behavior are discussed.

Anthony J. Pellechio Social Security Administration Room 320-I 1875 Connecticut Avenue, N.W. Washington, D.C. 20009

(202) $673-5730$ 


\title{
SOCIAL SECURITY AND THE DECISION TO RETIRE
}

\author{
Anthony J. Pellechio
}

\section{Introduction}

Social security is the major source of income support for retirement in the U.S.; the program paid benefits of approximately 105 billion in $1980 . .^{1}$ There are two broad views on how people are affected by social security. One view emphasizes that people retire because of poor health or because they are otherwise forced out of their jobs and that social security benefits compensate in part for the concomitant reduction in earnings. This view stresses the insurance aspect of social security with the implication that social security has little or no effect on when people retire. ${ }^{2}$ Another view based on economic models of labor supply allows for a potential effect of social security on retirement. This economic view has received considerable theoretical ${ }^{3}$ and empirical ${ }^{4}$ attention in recent years. Determining whether social security influences individual behavior, especially retirement, is important. Such information can be used to structure the system so that

1 Sources of information on benefit payments in the past and projected payments in the future are: Bayo, Ritchie, and Faber (1978); Petri(1980); Social Security Bulletin: Annual Statistical Supplement, Board of Trustees (1980), 1980 Annual Report.

2 Ball (1978), Myers (1964).

3 Sheshinski (1978), Diamond and Mirrlees (1978), Hu (1979), Kurz (1981), Crawford and Lilien (1981).

4 Campbel1 and Campbell (1976); Boskin (1977); Pellechio (1979a); Clark, Johnson, and Sumner (1981); Mitchell and Fields (1981); Esposito and
Packard (1980). 
it does not distort individual behavior and is financially sound. The purpose of this paper is to examine empirically whether social security influences the retirement decisions of individuals.

Social security can affect both an individual's decision to retire and, if he does not retire fully, his decision on how much to work. Based on these two dimensions of social security's effect on the labor supply, my empirical study of retirement has been divided into two parts. This paper presents the first part which focuses on the retirement decision and the influence that social security benefits can have upon this decision. A companion paper (Pellechio, 1981b) presents the second part of my study which examines how much retirement-aged individuals work when they do not retire fully. In this second part the social security earnings test, a regulation that reduces an individual's benefit payment when his earnings exceed a certain amount, enters the analysis. The econometric problems posed by the earnings test require a methodology for estimating labor supply over kinked budget constraints; this methodology has been developed in Pellechio (1979b). The examination of the separate effects of social security benefits and the earnings test on retirement is an important feature of this two-part study.

The framework for the empirical study here is the life-cycle model of individual behavior. The empirical specification of the model allows for testing whether the life-cycle model is a valid description of behavior. The way in which social security enters the model is presented in Section II. Briefly, what this section shows is that there 
are two main ways in which social security can affect behavior. One way is through the change in an individual's lifetime income that the system can bring about. Several studies ${ }^{5}$ have shown that the total amount an individual can expect to receive from social security does not necessarily equal what that individual paid into the system. In somewhat more precise terms, the present value of the benefits that an individual can expect to receive during retirement does not necessarily equal the present value of payroll taxes paid during his working career. Any difference between these two present values represents a change in lifetime income that has a potential income effect on economic behavior in general and retirement in particular.

The other way in which social security can affect retirement is by changing compensation for work. This can happen because benefits are based on earnings and will in general change in value in response to continued employment, i.e. delayed retirement. Any change in the value of benefits from delayed retirement becomes part of the compensation for work just like the money wages paid at the time of employment. Excellent discussions of this incentive to delay retirement in order to receive larger benefits in the future are given by Blinder, Gordon, and Wise (1980) and Bulow (1981). This study represents, in part, an attempt to measure responses to this incentive empirically. The main point is that by changing the compensation for work social security has potential substitution effects on how much people work. Social security's income and substitution effects are discussed in more detail 5 Pellechio (1981a); Ferrara (1980); Orlo and Schreitmueller (1978);
Leimer and Petri (1980). 
in Section II.

The model used for examining retirement decisions is based on the model of labor force participation that has become standard in the literature on labor supply. This model uses two equations, one for the market wage that an individual faces and another for the individual's value of time or shadow price. The market wage equation is expanded to include variables that measure social security's effect on an individual's compensation for work. Social security variables that influence an individual's shadow price are added to the shadow price equation. The final alteration that converts the standard labor force participation model into a retirement model is to define nonparticipation according to a suitable definition of retirement. The definition adopted here in effect implements the definition of retirement that is implicit. in the rules for receiving full social security benefits. With this definition the effect of these benefits on retirement can be examined independently of the earnings test. A description of the retirement model and techniques for identifying and estimating parameters are given in Section III.

The data used in this study come from the Social Security Administration. An important feature of the data is that it is possible to calculate accurately the social security benefit that an individual is entitled to receive. In other words, an individual's potential benefit is known even when no benefit payment is made. This benefit is used to construct the social security variables presented in Section II. Details on the empirical specification of the model are given in Section IV. 
Estimated retirement models for samples of retirement-aged men are given in Section $V$. The empirical results support the conclusion that social security affects the decision to retire. There are significant responses to the system's income and substitution effects and the magnitudes of these responses are presented and discussed. The results of this study and their implications for future behavior are summarized in Section VI.

\section{The Life-Cycle Model and Social Security}

The potential effects of social security on retirement will be discussed using the model of life-cycle behavior. ${ }^{6}$ In the absence of social security an individual chooses a path of lifetime consumption and labor supply by maximizing lifetime utility subject to the following constraint:

(1) $\sum_{t=1}^{T} \quad c_{t} D_{t}=\sum_{t=1}^{R-1} w_{t}{ }_{t} D_{t}$

6 Two excellent theoretical models of life-cycle behavior are given by Blinder and Weiss (1976), and Heckman (1976). Versions of the lifecycle model that add social security in a way similar to what is done here are given by Feldstein (1976b), Samuelson(1975), Kotlikoff (1979), and $\mathrm{Hu}$ (1979). 
where $T=$ number of years of an individual's life

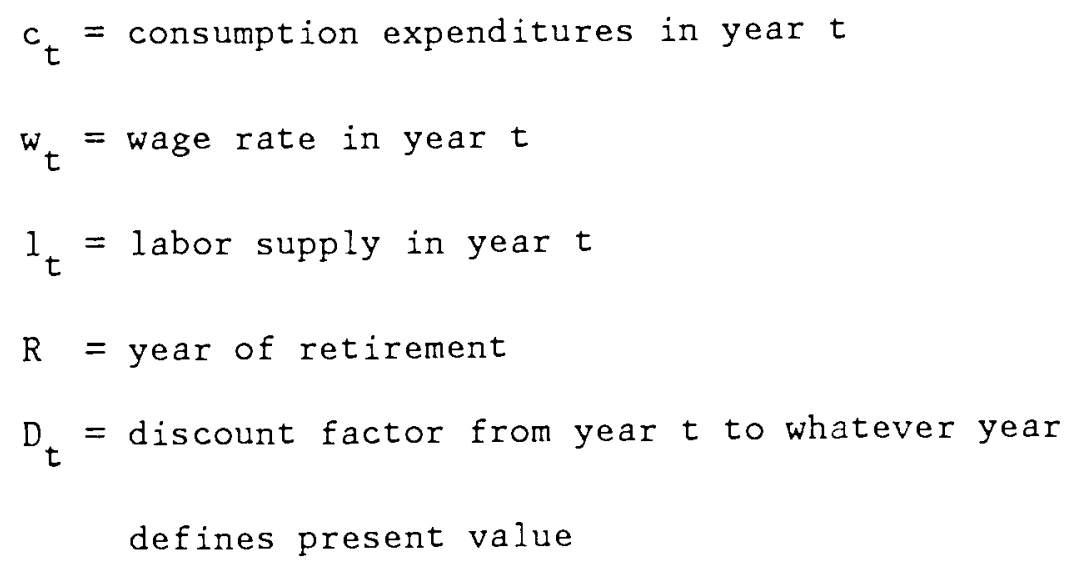

This simply says that the present value of total lifetime consumption expenditures must equal the present value of total lifetime earnings.

The adjustment to equation ( 1 ) for social security entails reducing an individual's earnings during his working career by the payroll taxes he pays and increasing his income during retirement by the benefits he receives. The lifetime budget constraint becomes:

$$
\sum_{t=1}^{T} c_{t} D_{t}=\sum_{t=1}^{R-1}\left(1-p_{t}\right) w_{t}{ }^{1} D_{t} D_{t}+\sum_{t=R}^{T} B_{t} D_{t}
$$

where $p_{t}=$ payroll tax rate in year $t$

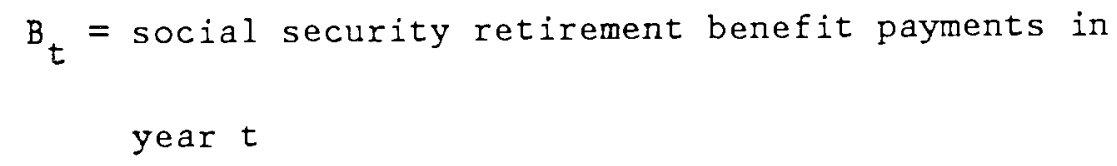

The first term on the right-hand side of equation (2) can be separated into two components as follows: 
(3a) $P V E=\sum_{t=1}^{R-1} w_{t}{ }^{1} D_{t}=$ present value of earnings

(3b) $\quad$ PVTAX $=\sum_{t=1}^{R-1} p_{t} w_{t}{ }^{1} D_{t}=$ present value of payroll taxes

The second term on the right-hand side of equation (2) equals the actuarial present value of the social security benefits to which an individual is entitled as a retired worker; the survival probabilities that make it an actuarial calculation are included in the $D_{t}$ 's.

This present value of benefits is called "social security wealth" and is denoted SSW. ' If SSW equals PVTAX then equation (2) is the same as equation (1) which means that social security does not change lifetime income." However, as was pointed out before (see n. 5), SSW does not necessarily equal PVTAX. When SSW exceeds PVTAX social security has raised an individual's lifetime income. The life-cycle model predicts a potential decrease in labor supply on the usual assumption that leisure is a normal good. This decrease could occur as a reduction in labor supply $\left(l_{t}\right)$ in the years in which a person works or a reduction in 7 Social security wealth was defined and first calculated by Feldstein
$(1976 a)$.

- Whether social security can affect behavior is a question with diverse answers. Crawford and Lilien (1981) show in a theoretical model how behavior can be affected by social security even when it does not change lifetime income, i.e. when it is actuarially fair. In another theoretical model with perfect capital markets and fixed labor supply Barro (1974) shows that social security has no economic effects even if it is not actuarially fair. 
the number of years of work $(R-1)$. Of course, if SSW is less than PVTAX labor supply may be affected in the opposite way, i.e. individuals may work more per year or increase their number of years of work. The overall point is that SSW - PVTAX measures the change in lifetime income produced by social security and this change has a potential income effect on retirement.9

Another effect of social security comes from the influence that an additional year of earnings can have on an individual's present and future benefit payments. The influence on present benefit payments arises because an individual foregoes current benefits when he decides not to retire. The effect on future benefits arises from the fact that earnings are used to calculate benefits. To see these effects consider the change in the budget constraint when a person works rather than retires in year $R^{10}$

9 Barro's (1974) theory of life-cycle behavior with bequests implies that there is no lifetime income effect. Intergenerational transfers would cancel any change in an individual's lifetime income that social security might try to impose. However, Barro's argument rests on his assumption that labor supply is fixed. This paper examines whether labor supply responds to changes in the lifetime budget constraint produced by social security. Information on bequests is needed along with the data used here (see Section IV) to examine Barro's theory. The results here do not refute Barro's model but do stand in juxtaposition to his assumption of fixed labor supply.

10 The year that defines present value is taken to be $R$ so that $\mathrm{D}_{\mathrm{R}}=1$. 
(4)

$$
\sum_{t=1}^{T} c_{t} D_{t}=P V E+S S W-P V T A X+\left(1-p_{R}\right) w_{R} 1_{R}-B_{R}+\sum_{t=R+1}^{T}\left(B_{t}^{\prime}-B_{t}\right) D_{t}
$$

where $B_{R}=$ foregone benefits in year $R$

$$
\begin{aligned}
B_{t}^{\prime}= & \text { the benefit obtained in year } t \text { by adding earnings } \\
& \text { in year } R \text { to the benefit calculation }
\end{aligned}
$$

The term $\left(1-p_{R}\right) w_{R}{ }_{R}$ denotes the individual's net

earnings from working in year $R$. The last two terms in equation (4)

represent the two ways in which social security can affect the compensation from work. One way has to do with the fact that benefits are foregone in year $R$ by working. The $-B_{R}$ term represents this loss in current benefits. This loss reduces the compensation from work and as such raises the likelihood of retirement.

The second way in which social security can affect compensation for work is through the influence that earnings can have on future benefits. Excellent discussions of this point are given by Blinder, Gordon, and Wise (1980) and Bulow (1981). The issue arises because an average of an individual's earnings is used to calculate benefits. ${ }^{1}$ Earnings in the current year tend to increase this average because they are likely to be

11 The calculation of benefits begins by calculating the average of an individual's annul earnings from age 22 through the year before retirement. Only earnings up to a maximum amount in each year are used. In 1972, the year of this study, the social security system computed the simple average of actual earnings after dropping the five years of lowest earnings, i.e. no adjustment was made for different wage or price levels in different years. This simple average is the base for calculating benefits; in other words, $a$ benefit formula is applied to this average to yield a benefit amount. 
higher in nominal terms, if not in real terms, than past earnings. An earnings-induced increase in future benefits is denoted by

$B_{t}^{\prime}-B_{t}$ in the last term of equation (4). The present

value of any increase in future benefits constitutes additional

compensation for work and this additional compensation makes retirement less attractive and therefore less likely. This present value is given by the last term in equation (4) and will be denoted DSSW.

Both the influence of foregone current benefits and increased future benefits come under the heading of a substitution effect in the sense that they change the compensation for work and as such can change how much people work. Compensation for work is decreased by the loss in current benefits, $-B_{R}$, and increased by any gain in the value of future benefits, DSSW. Thus, the main point of equation (4) is that social security has two potential substitution effects that work in opposite directions. The variables needed to estimate these substitution effects as well as the income effect discussed in this section are included in the retirement model constructed in the next section.

\section{The Retirement Model}

The labor force participation model developed in the labor supply literature 12 is used to construct an econometric model for examining retirement behavior. The model uses equations that describe an

12 Gronau (1973, 1977); Hal1 (1975); Hanoch (1976); Heckman (1974). 
individual's total compensation for work and his value of time in nonmarket activities or shadow price. Let an individual's market wage, $w$, be given by the following equation:

(5) $w=x_{\alpha}+e_{1}$

where $X$ is a set of variables measuring wage, $\alpha$ is the vector of coefficients for $X$, and $e_{i}$ is an error term.

As discussed in Section II, a person's compensation for work equals his market wage and any earnings-induced change in the value of current or future benefits. A loss of current benefits, denoted $B_{R}$ as before; reduces compensation and a gain in the value of future benefits, denoted DSSW, raises compensation. An individual's compensation for work, denoted $v$, is therefore given as follows:

$$
\begin{aligned}
v & =c_{1} B_{R}+c_{2} D S S W+w \\
& =c_{1} B_{R}+c_{2} D S S W+x_{\alpha}+e_{1}
\end{aligned}
$$

The coefficients of $B_{R}$ and DSSW should ideally equal -1 and 1 respectively. However, they are left open to empirical estimation and given as $c_{1}$ and $c_{2}$ in equation $(6) ; c_{1}$ is expected to be negative and $c_{2}$ positive. 
The decision to retire also depends on the value of an individual's time in activities other than working in the labor market, i.e. his opportunity cost or shadow price. The lifetime income effect discussed in Section II arises because a change in lifetime income has a potential effect on an individual's shadow price. For example, an increase in lifetime income makes it possible to spend more time outside the labor market and therefore raises an individual's shadow price. As shown in Section II, the change in lifetime income produced by social security is given by the difference between social security wealth and the present value of payroll taxes. The number of hours an individual spends working also affects his shadow price. The more an individual works the more valuable leisure time is to him. So, as hours of work go up so does shadow price. The equation for shadow price, denoted $s$, is given as follows:

$$
s=b_{1} S S W+b_{2} \text { PVTAX }+b_{3} h+Y B+e_{2}
$$

where SSW and PVTAX denote social security wealth and the present value of payroll taxes as defined in equations (2) and (3b) of Section II, $h$ equals hours of work, $Y$ is a set of additional variables that influence shadow price, $\beta$ is the vector of coefficients for $Y$, and $e_{2}$ is an error term.

A strict interpretation of the life-cycle model implies that an individual responds to the change in lifetime income brought about by social security; Section II showed this change to be SSW - PVTAX. A consequence of this is that the coefficients of SSW and PVTAX should be 
equal in magnitude and opposite in sign. These coefficients will be estimated freely. Examining whether $b_{2}=-b_{1}$ serves as a test of the life-cycle model.

The definition of retirement used in this study says that a person is retired when his earnings are low enough so that there is no. reduction in his social security retirement benefit payment due to the earnings test. In other words his earnings are below the amount at which the earnings test begins to reduce benefit payments - called the exempt amount. Let $\mathrm{K}$ denote the number of hours of work it takes an individual to earn the exempt amount. In the terminology of the model a person is retired when the shadow price of his time at $h=K$ exceeds $h$ is compensation for work. In terms of equations (6) and (7) this means:

$$
b_{1} S S W+b_{2} \text { PVTAX }+b_{3} K+Y B+e_{2}>c_{1} B_{R}+c_{2} \text { DSSW }+X_{\alpha}+e_{1}
$$

or,

$$
e_{2}-e_{1}>c_{1} B_{R}+c_{2} \text { DSSW }-b_{1} S S W-b_{2} \text { PVTAX }-b_{3} K+X_{\alpha}-Y B
$$

Let $D R$ be a binary variable that indicates whether a person is retired $(D R=1)$ or not $(D R=0)$. The probability of retirement, $P(D R=1)$, equals the probability that equation (9) holds which depends on the distributions of $e_{1}$ and $e_{2}$. Let $e_{1}$ and $e_{2}$ be

distributed normally with variances $\sigma_{1}^{2}$ and $\sigma_{2}^{2}$,

respectively, and covariance $\sigma_{12}$. In this case $e_{2}-e_{1}$ is

also normally distributed with variance $\sigma^{2}=\sigma_{1}^{2}+\sigma_{2}^{2}-2 \sigma_{12}$. 
Letting $F$ denote the standard normal distribution function, the retirement probability becomes:

$$
\begin{gathered}
P(D R=1)=1-F\left[\left(c_{1} B_{R}+c_{2} D S S W-b_{1} S S W-b_{2} P V T A X-b_{3} K\right.\right. \\
\left.\left.+X_{\alpha}-Y \beta\right) / \sigma\right]
\end{gathered}
$$

The argument of $\mathrm{F}$ will be called the "retirement index" and denoted $\mathrm{J}$.

$$
\text { Estimates of } c_{1}, c_{2}, b_{1}, b_{2}, b_{3}, \alpha \text {, and } \beta \text { up }
$$

to a scale factor $\sigma$ can be obtained from a probit analysis of DR. This is done by dividing a sample of individuals into the subsamples of those who are retired, $\{D R=1\}$, and those who are not, $\{D R=0\}$, and maximizing the likelihood of observing this behavior in the sample. The likelihood function following from equation (10) that is maximized is:

$$
L=\prod_{i \varepsilon\{D R=1\}}\left[1-F\left(J_{i}\right)\right] \quad \prod_{i \varepsilon\{D R=0\}} F\left(J_{i}\right)
$$

where $J_{i}=$ the value of the retirement index using individual's values for the variables.

In this way maximum likelihood estimates of $c_{1} / \sigma, c_{2} / \sigma$, $\mathrm{b}_{1} / \sigma, \mathrm{b}_{2} / \sigma, \mathrm{b}_{3} / \sigma, \alpha / \sigma$, and $\beta / \sigma$ are obtained.

It is important to point out that the above retirement model is valid even in the presence of the social security earnings test. The effect of the earnings test on the individual budget constraint is illustrated in Figure 1. The social security benefit that an individual could receive in retirement is represented by the vertical distance $A B$. 
FIGURE 1

THE EARNINGS-TESTED BUDGET CONSTRAINT

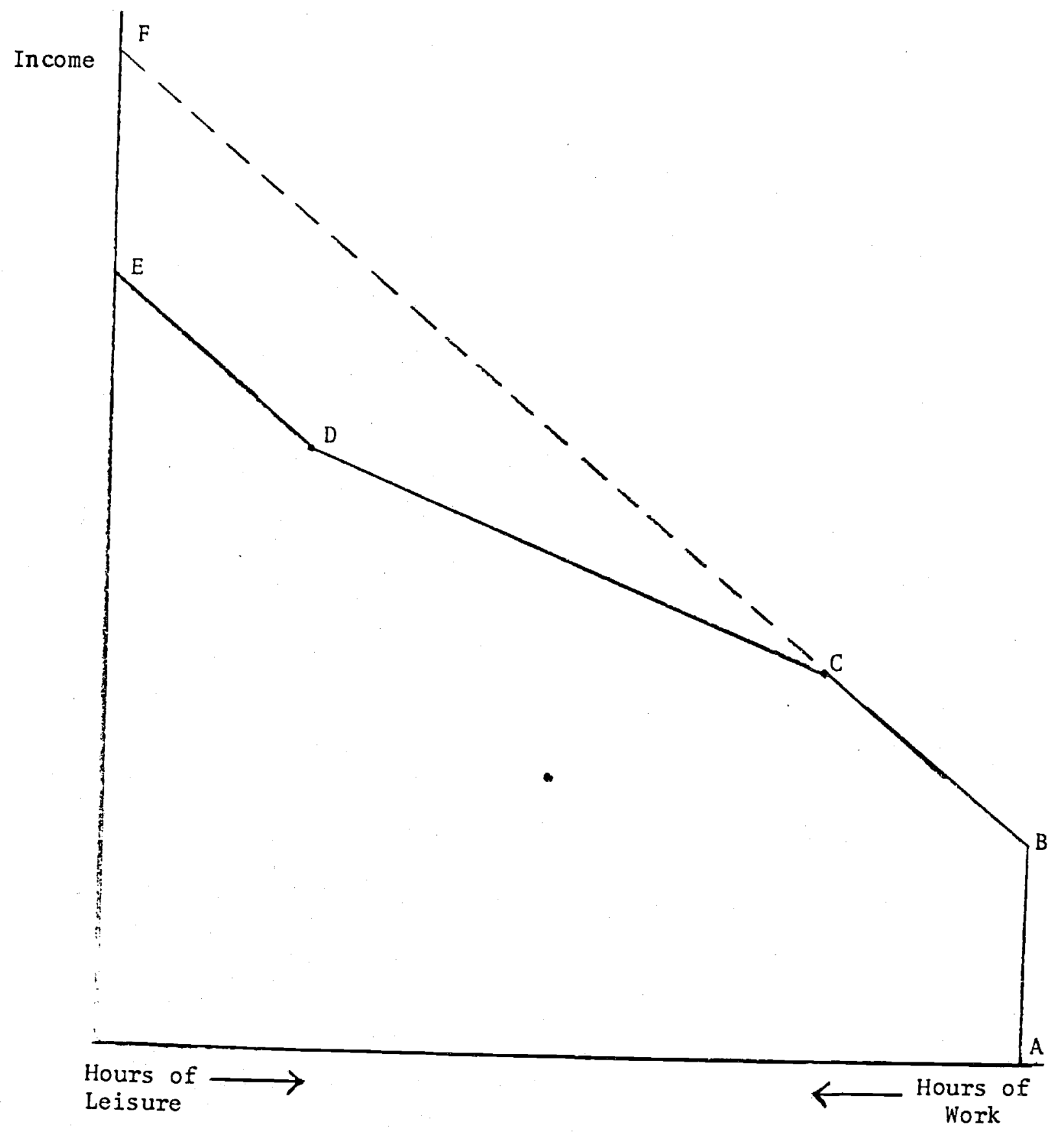


The variable $\mathrm{B}_{\mathrm{R}}$ in the model is measured by this distance. As

Figure 1 shows, the budget constraint is divided into three segments by the earnings test. On the first segment, points B to C, a person can receive his full retirement benefit and earn income up to the exempt amount without losing benefits. Along the second segment, points $C$ to $D$, benefit payments are reduced by $\$ .50$ for every $\$ 1.00$ of earnings above the exempt amount. This effectively reduces a person's wage by 50 percent and, as the figure shows, the slope of the budget constraint drops in magnitude. Once benefit payments are reduced to zero at point D a person goes back to receiving his full wage above this point. Due to this increase in wage from 50 percent to its full amount, the budget constraint is nonconvex around point $D$. The overall effect of the earnings test on the individual budget constraint is to make it kinked and nonconvex.

The crucial feature of the earnings-tested budget constraint for the analysis here is that the extension of its initial segment $B C$, given by the dashed line $C F$ in Figure 1 , lies above the rest of the constraint. In this situation when an individual's shadow price at point $\mathrm{C}$ is greater than his compensation for work there is no chance of the reverse happening above point $C$. In other words, equation ( 9 ) is a necessary and sufficient condition for retirement. This would not be the case if the budget constraint, because of a nonconvexity, did lie above CF at some point. It would then be possible both for equation (9) to hold indicating a decision to retire and for an individual's shadow price to be less than or equal to the slope of a portion of the budget constraint above CF which indicates a'willingness to work above point $\mathrm{C}$, 
i.e. a decision not to retire. However, this problem does not arise with the earnings-tested budget constraint as illustrated in Figure 1 , and equation (9) remains a complete description of retirement. ${ }^{13}$

It is important to point out that the slope of the budget constraint equals the individual's compensation for work and not his wage alone. As such it includes the value of any earnings-induced increase in the value of future benefits. This additional compensation could result in the budget constraint lying above its initial segment. Blinder, Gordon, and Wise (1980) focus attention on this additional compensation and how it affects the budget constraint. They find that in some cases this additional compensation approximately cancels the implicit tax rate of 50 percent in the earnings test. A cancellation of the earnings test would not affect the analysis here; it would just imply that point $C$ is not a very important point to focus attention on and that $\mathrm{K}$ is not an important variable. The important question that Blinder, Gordon, and Wise raise is whether individuals understand or perceive this additional compensation and change their retirement behavior in response to it. This additional compensation was presented as the variable DSSW in Section II and is included in the retirement model that is estimated here. Given the data used in this study DSSW can be accurately calculated. By including DSSW in the empirical specification of the retirement model I attempted to find out whether

13 Because the budget constraint has the above-mentioned feature the effect of the earnings test at point $C$ and above can be excluded from for the division of my study provides the technical justification The effect of the earnings test retirement behavior into two parts. aged individuals is studied in the the hours of work of retirementto this one. 
the work incentive discussed by Blinder, Gordon, and Wise and in Section II affects individual retirement decisions empirically. The data and calculation of variables in the empirical analysis are described next.

\section{Data and Empirical Specification}

2.2. The empirical analysis is based on a rich file of data from the Social Security Administration -- the 1973 CPS-IRS-SSA Exact Match file. ${ }^{24}$ This file starts with the March 1973 Current Population Survey (CPS). Each individual's CPS record is matched to extracts of his 1972 income tax return (IRS) and social security records (SSA). The sample drawn from this file for empirical study here consists of married men age 60 - 70 who are entitled to social security retirement benefits.

The social security data permit precise calculation of the social security variables mentioned in previous sections. The reason for this is that annul earnings covered by social security and the number of quarters of coverage in each year from 1951 through 1975 are given for each individual. This earnings information is precisely that used by the Social Security Administration to calculate benefits. Benefits for each individual were calculated according to the law in 1972 , the year for which the CPS gathered information and in which retirement behavior is being examined in this study. The benefit variable, denoted BEN, in the empirical specification of the model equals the retirement benefit

14 Aziz (1978). 
that the couple is entitled to receive based on the earnings histories of the husband and the wife and the allowance for a dependent spouse. It is important to point out that the calculation of this variable in no way depends on their earnings in 1972. It is a potential benefit, not an actual benefit payment, and as such is exogenous with respect to the behavior in 1972 being estimated.

The benefit payments that the husband and wife are entitled to receive in the future if they retire in 1972 are also projected according to the law. Social security wealth, SSW, equals the actuarial present value of these benefit payments. The actuarial part of the calculation takes into account the probabilities that husband and wife each survive to years in the future. In this study the potential benefit payment in a future year is multiplied by the probability of surviving to that year. ${ }^{15}$ If the husband's own benefit is under consideration then the probability of his surviving to that year is used. If a dependent spouse benefit is under consideration then the probability that both survive is used. If a survivors benefit is under consideration then the probability that the partner who is being considered the survivor survives and the other partner does not is used. The survival probabilities used here are the latest available from the Bureau of the Census. ${ }^{16}$ These probabilities are given by sex and age and

15 The use of survival probabilities in this study rather than life expectancies as in other studies is an important difference worthy of note. These other studies assume individuals live to their life expectancies. I do not know how life expectancies could be used to account for the contingencies discussed in the following sentences in
the text.

16 U.S. Department of Commerce. Bureau of the Census. Projections of the Population of the United States: 1977 to 2050 Series P-25, No. 704 , July 1977 . 
incorporate improvements in survival rates to the year 2050 . Benefit payments in future years are also discounted at a real interest rate of 1 percent.

The present value of an individual's earnings and the present value of the payroll taxes he paid over his working career are calculated from the social security earnings data. These variables are denoted PVE and PVTAX and equation (3) gives the formula for each. It is important to note that PVE is the present value of covered earnings and as such falls short of encompassing a person's entire lifetime earnings. PVTAX is computed accurately from covered earnings. Earnings and payroll taxes in past years are converted into dollars of present value, i.e. 1972 dollars, at the same real interest rate of 1 percent as were benefits in future years in the calculation of SSW.

The social security earnings data are also used to compute a wage variable for each individual. This computation uses earnings in the years 1967-71 to produce a variable measuring a person's potential fulltime earnings in 1972. In order to do this a limitation in the earnings data had to be overcome. This limitation is that earnings only up to the maximum amount taxed by social security are reported. However, along with these earnings the data report the number of quarters in which the individual had covered earnings during the year. If an individual earned the taxable maximum in any year a procedure developed by Fox (1976) that approximates earnings above the maximum based on the number of quarters it took to reach the maximum is employed here. This procedure is used to calculate full-year earnings. An approximation to full-year earnings is also made when an individual did not earn the 
taxable maximum but had less that four quarters of coverage. Thus, the first step in constructing a wage variable is to use actual earnings and quarters of coverage in 1967-71 to calculate full-year earnings in those years. The objective is to convert actual earnings which may depend on labor supply into a wage variable that does not depend on labor supply.

After computing full-time earnings in 1967-71, earnings in each year are converted to 1972 dollars. This is done by increasing fulltime earnings in a particular year by the rate of increase in average wages in the population as a whole between that year and 1972. Finally, full-time earnings in 1967-71 expressed in 1972 dollars are averaged to yield the variable used as the measure of a person's potential market wage in 1972. This variable is calculated for both husband (WAGE) and wife (WAGEW).

The number of years of past earnings used to construct the wage variable is of course arbitrary. However by considering using more past years an important issue is raised. It can be argued that a person's entire history of earnings and labor supply should be used to examine his behavior in any particular year. An implication of this is that it is possible to consider using all past annual earnings to compute WAGE. However, this would cause problems for a study such as this where the objective is to examine whether social security influences retirement decisions independently of other variables. The reason is that social security benefits are computed from a person's entire history of earnings. It would be difficult to estimate an effect of social security independently of other variables if the assertion is made that these other variables include all the information that goes into 
calculating social security benefits. This would be the case if WAGE were computed from all previous earnings.

It is important to point out that this issue arises in any empirical study of retirement, not just this one. Consequently there is an identifying assumption in this and any other retirement study that should be made explicit. The assumption is that there is a difference between the way in which past earnings affect current behavior and the way in which social security benefits, as computed from past earnings, affect current behavior. The form that this identifying assumption takes in this study is that the wage variable is computed from the previous five years of earnings, and social security benefits are computed according to the law from the entire earnings history. In other words, benefits depend on an earnings history that is longer than that which directly affects behavior, and therefore can have an exogenous effect on retirement.

Given a person's potential earnings it is possible to figure out how his benefit would change if an additional year of earnings were included in the benefit formula. This is done in order to calculate the variable DSSW discussed in previous sections. DSSW equals the present value of any increase in future social security benefits that can be gained from working an additional year and adding another year of earnings to the benefit calculation. Operationally, a person's average earnings as specified by social security law is recomputed with earnings in 1972 set equal to his potential earnings. The benefit that a person would be able to receive based on this new average earnings at the end of 1972 is calculated using the same benefit formula used to calculate 
benefits in 1972. DSSW equals the present value of the difference between this benefit and the benefit he would receive if he did not work, i.e. retired, in 1972. Discounting in the calculation of DSSW is done at the same real interest rate of 1 percent used in the other present value variables.

Table 1 illustrates the magnitude of the variables discussed up to this point. The table reports retirement rates, social security wealth, social security benefits, and DSSW by potential earnings (WAGE) brackets and age groups in 1972. The definition of retirement is that a person's earnings in 1972 are less than the exempt amount in the earnings test for that year, which was $\$ 1,680$. The age groups in the table are those over which the retirement model was estimated; results are presented in the next section. The benefit is the combined benefit that the husband and wife are entitled to receive. SSW is the present value of the benefit payments to both the husband and wife. In the bracket where the mean value of potential earnings of $\$ 8,967$ for $62-64$ year olds falls the table shows that the retirement rate is .257 , social security benefits equal $\$ 4,576$, SSW equals $\$ 80,830$, and DSSW equals $\$ 2,275$. In the potential earnings bracket containing the mean value of potential earnings for 65 - 70 year olds the retirement rate is .695 , social security benefits are $\$ 4,508$, SSW equals $\$ 73,143$, and DSSW equals $\$ 1,358$.

Another variable in the retirement model is the number of hours of work it would take to earn the exempt amount in the earnings test. It appears because a person's shadow price depends on how much he works. This variable is denoted $K$ and equals $\$ 1,680$, the exempt amount in 1972 , 
TABLE 1

SUMMARY STATISTICS BY WAGE BRACKETS

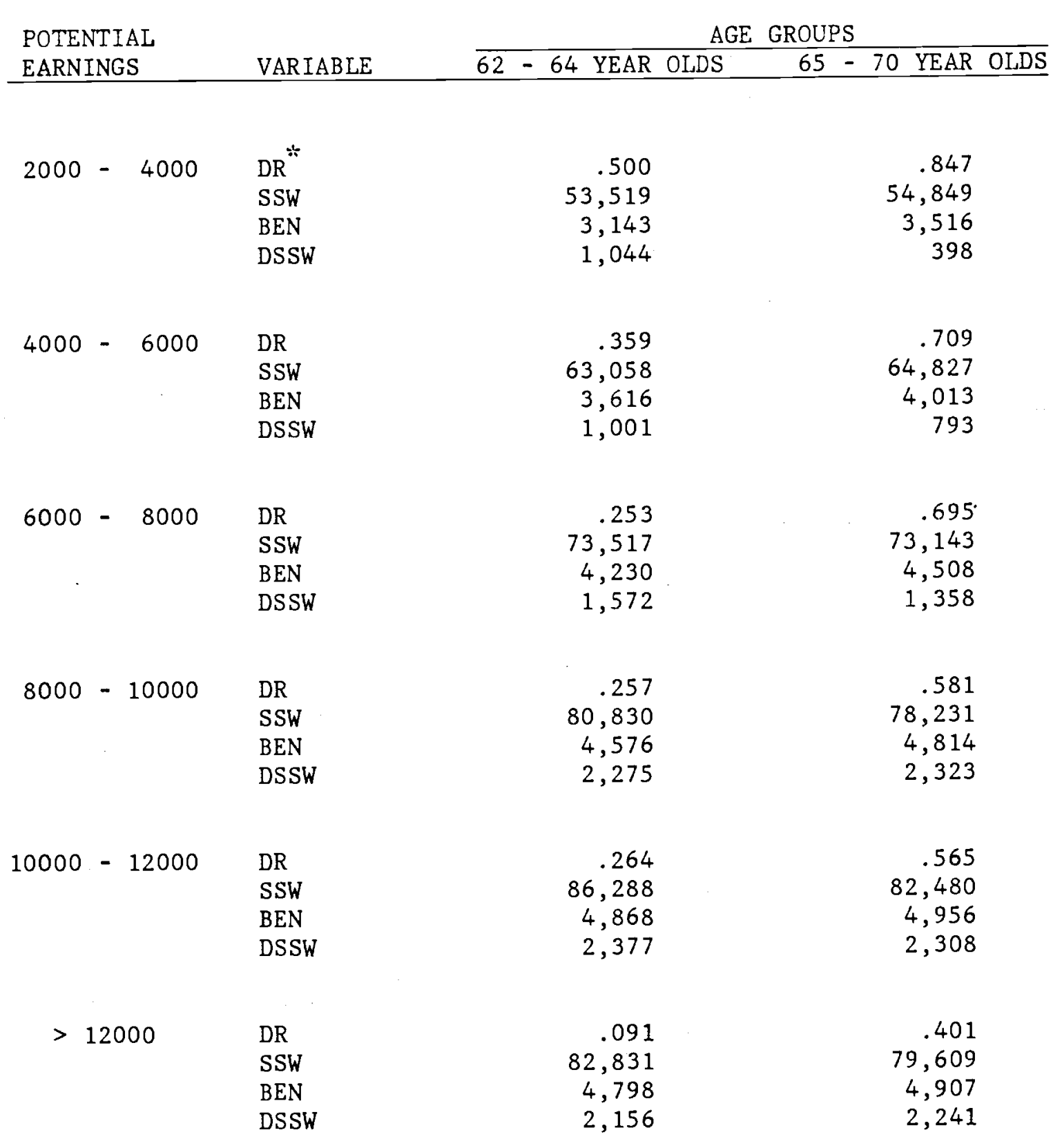

* The mean of DR equals the observed retirement rate. 
divided by a person's wage. Since the wage variable WAGE equals a person's annual wage, $K$ equals $\$ 1,680$ divided by WAGE and multiplied by 2080, the number of hours of work in a full-time year. Since the exempt amount is the same for everyone, $K$ is really just the inverse of WAGE. As such it does not measure any response to changes in the earnings test. Thus, $K$ may be more properly regarded as a variable measuring a nonlinear wage effect. If the effect of wage were taken to be strictly linear by assumption then the inverse of wage would measure the coefficient of hours of work in the shadow price equation as specified in equation ( 7 ). An exact interpretation of $K$ is not an important point in this study. It is important to realize that the wage effect is given by both the coefficient of WAGE and that of $K$.

Some additional variables that appear in labor force participation models can be defined from the data used here and included in the empirical specification of the retirement model. One such variable is capital income, denoted KINC. The CPS data report capital income as the sum of interest payments, dividends, rental income, and other property income. The IRS data report total dividends and the taxable portion of interest payments. The larger of the amounts reported by the CPS and IRS as capital income is taken to be KINC.

Other variables that appear in the empirical specification of the retirement model are the husband's and wife's age (AGE and AGEW, respectively) and number of years of schooling (ED and EDW, respectively). There are also binary variables to denote race (RACE $=1$ for whites) and residence in a rural area (RURAL). 
MEANS AND STANDARD DEVIATIONS OF VARIABLES IN THE RETIREMENT MODEL

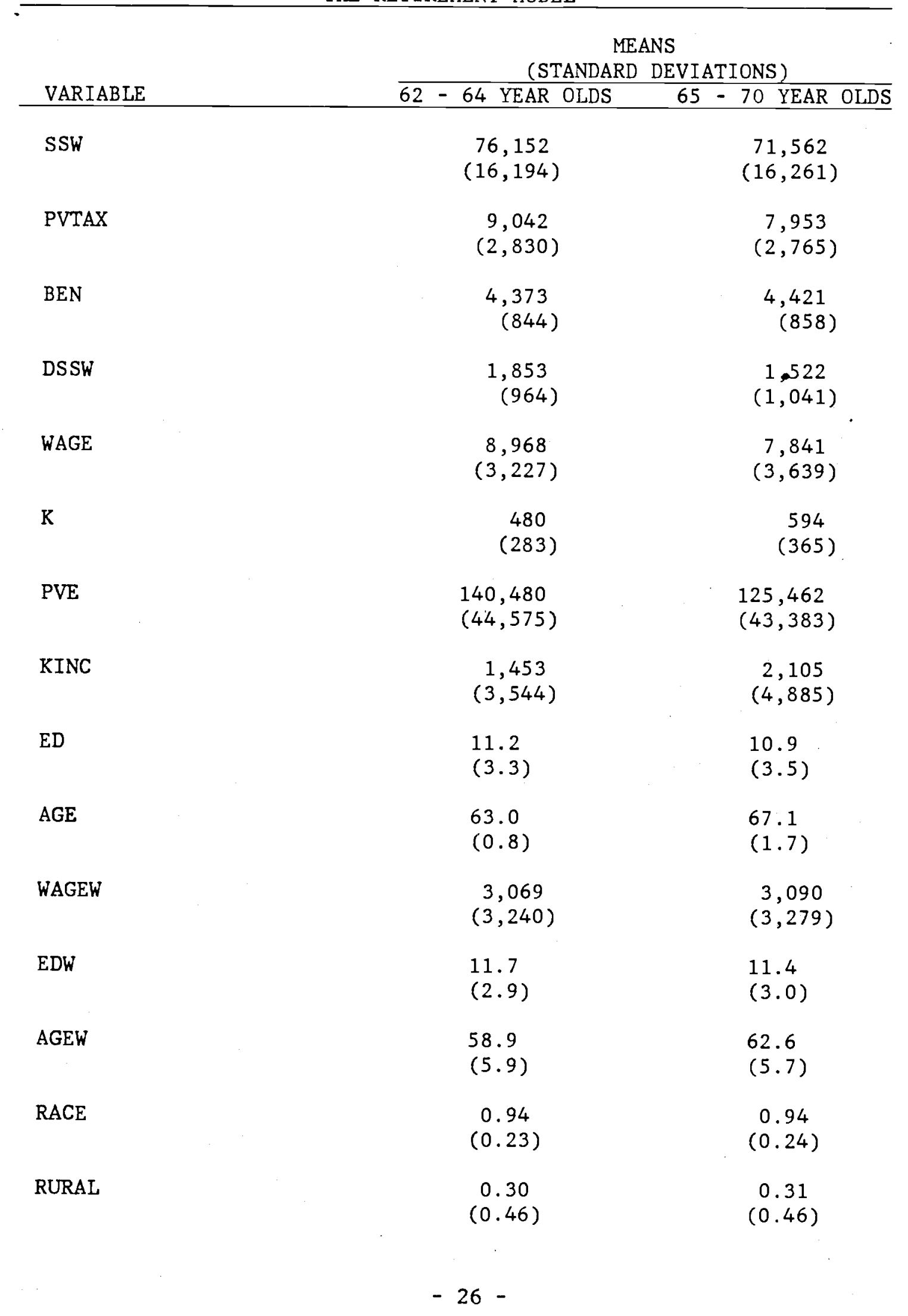


The means and standard deviations of the variables appearing in the retirement model for the two age groups are given in Table 2 . The empirical specifications of the equations for compensation for work and for shadow price, i.e. equations (6) and (7) in Section III, are:

$\left(6^{\prime}\right) \quad v=c_{1} B E N+c_{2}$ DSSW $+c_{3}$ WAGE $+c_{0}+e_{1}$

$\left(7^{\prime}\right) \quad s=b_{1} S S W+b_{2}$ PVTAX $+b_{3} K+b_{4} P V E+b_{5} K I N C+b_{6} E D+b_{7} A C E+$ $b_{8}$ WAGEW $+b_{9} E D W+b_{10}$ AGEW $+b_{11}$ RACE $+b_{12}$ RURAL $+b_{0}+e_{2}$

Estimates of the retirement model defined by these equations are presented next.

\section{Empirical Results}

This section presents estimated retirement models for the sample of married men drawn from the 1973 Exact Match file. These men are eligible to receive social security benefits. They did not receive public assistance income in 1972. They were not covered by the railroad retirement system. Their full-time annual earnings as given by the variable WAGE described in the last section were greater than or equal to $\$ 2000$. These criteria represent an attempt to exclude any potential behavioral effects of low income support provided by programs other than social security. In other words, attention is focused on social security's potential influence on retirement decisions. 
Estimates of the retirement model were obtained by maximizing the likelihood function given by equation (11) using the variables given in Table 2 for the sample of married males. The empirical specification of the retirement index $\mathrm{J}$ used in the likelihood function is:

$$
\begin{aligned}
J= & \left(b_{1} \text { SSW }+b_{2} \text { PVTAX }+c_{1} \text { BEN }+c_{2} \text { DSSW }+c_{3} \text { WAGE }+b_{3} K+\right. \\
& b_{4} \text { PVE }+b_{5} \text { KINC }+b_{6} \text { ED }+b_{7} \text { AGE }+b_{8} \text { WAGEW }+b_{9} \text { EDW + } \\
& \left.b_{10} \text { AGEW }+b_{11} \text { RACE }+b_{12} \text { RURAL }+b_{0}^{\prime}\right) / \sigma
\end{aligned}
$$

where $\sigma$ equals the standard deviation of the difference between the error terms, $e_{2}-e_{1}$, in the shadow price and compensation for work equations. Thus, probit analysis produces estimates of coefficients relative to $\sigma$. Table 3 presents the probit estimates of coefficients.

Estimates of the retirement model were obtained separately for $62-64$ and 65 - 70 year olds. The results in Table 3 provide overall support for the life-cycle approach taken here and the conclusion that social security has significant effects on retirement decisions. As was pointed out in previous sections, the life-cycle model leads to the hypothesis that the coefficient estimates for SSW and PVTAX should be equal in magnitude and opposite in sign. The coefficient estimates are significantly different from zero and have opposite signs but the magnitudes are not equal. Nonetheless, the coefficient estimates for both SSW and PVTAX indicate that social security has a strong lifetime income effect on retirement. The difference in magnitude says that the lifetime income effect of benefits is different from that of taxes. The positive coefficient for SSW and negative coefficient for PVTAX both 


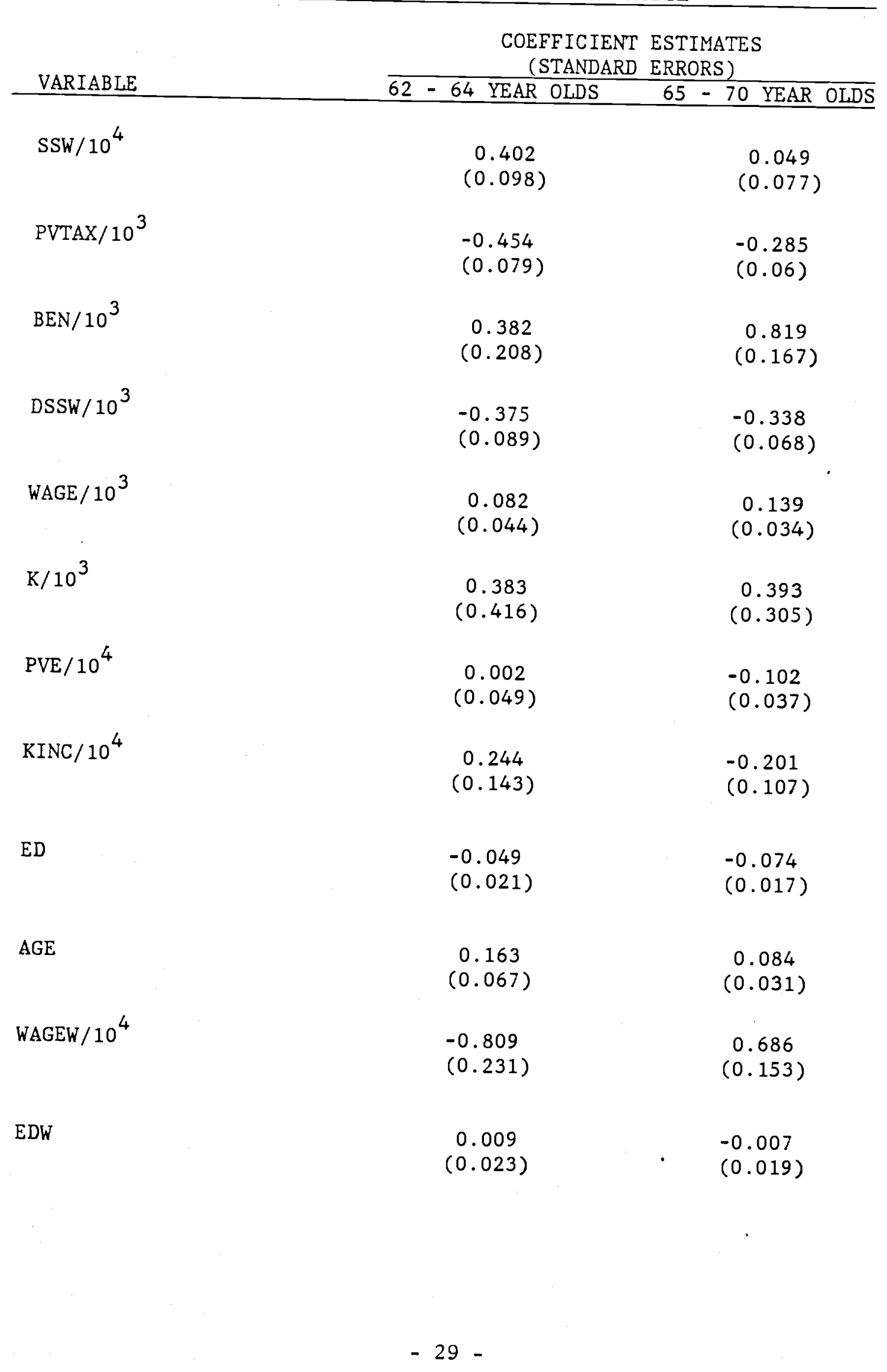


TABLE 3 -- continued

PROBIT ESTIMATES OF THE RETIREMENT MODEL

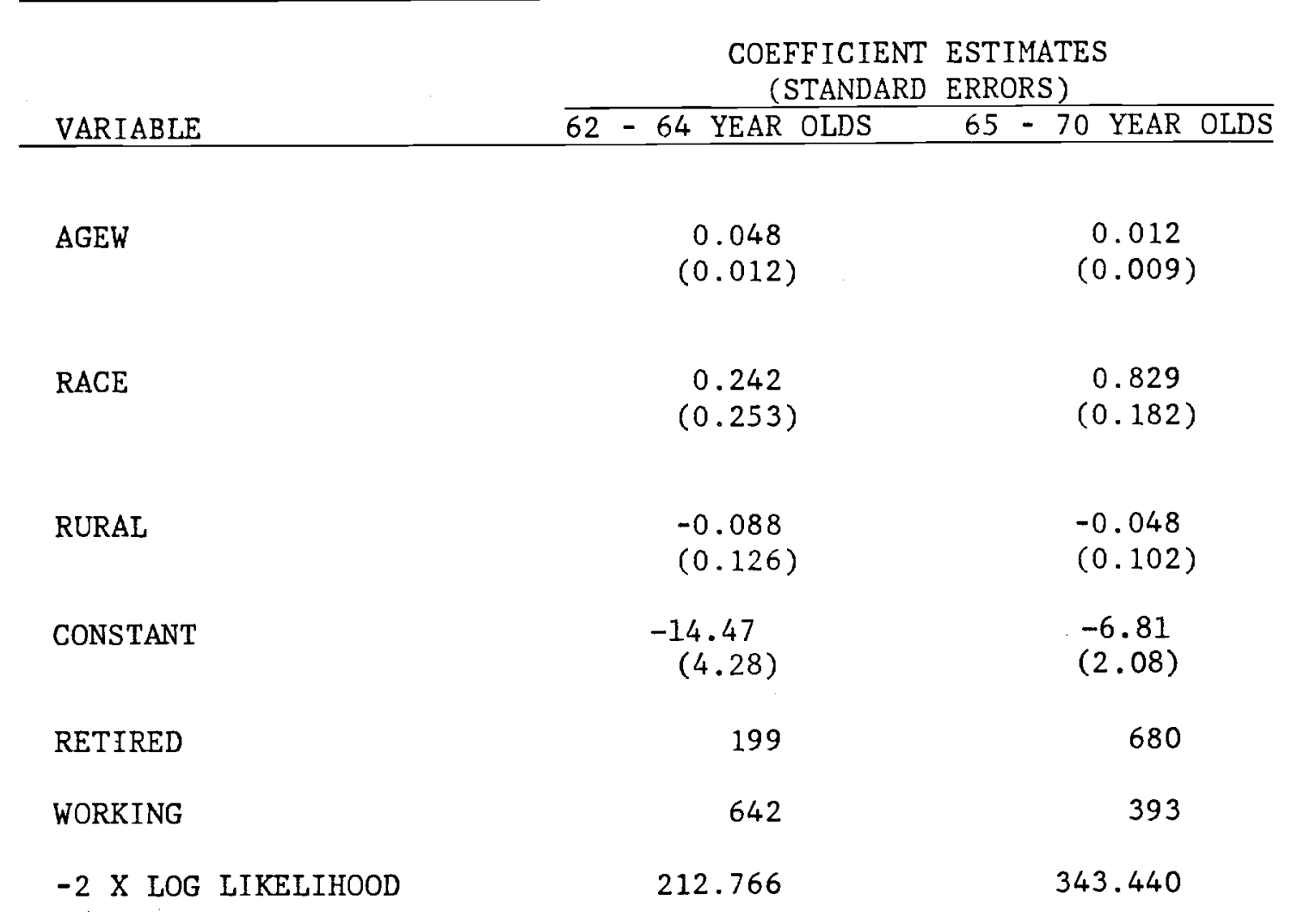


imply that an increase in lifetime income obtained through social security raises the probability of retirement.

The estimated substitution effects of social security conform with expectations. The benefit variable BEN measures the current social security benefit that would be lost if the individual did not retire. Such a loss in benefits reduces the compensation for work and should raise the probability of retirement. The positive coefficient estimate for BEN indicates that this is what happens empirically. DSSW equals the present value of the increase in future benefits obtained when a person continues to work and adds another year of earnings to the benefit calculation. DSSW represents extra compensation for work and as such should encourage work and lower the probability of retirement. The negative coefficient estimate for DSSW provides empirical evidence that this is the case.

It is interesting to note that the coefficient estimates for BEN and DSSW have nearly the same magnitude for 62 - 64 year olds. The difference in their magnitudes is statistically insignificant. When the compensation for work equation, equation (6), was specified the fact that the coefficients for BEN and DSSW should have the same magnitude was pointed out. Although this should hold for 65 - 70 year olds as well, it does not. This suggests that older individuals respond more to the substitution effect of a loss in current benefits rather than that of an increase in future benefits. In other words, older individuals are more inclined to collect current benefits and less willing to respond to the work incentive in the social security benefit formula. 
The magnitude of the effect of a change in a variable on the probability of retirement is not immediately apparent from the estimates given in Table 3. In order to calculate such effects it is necessary to start with the estimated probability of retirement given by the model:

$$
\hat{P}(D R=1)=\int_{-\infty}^{-\hat{J}} f(t) d t
$$

where $\hat{J}$ is the estimate obtained from Table 3 of the retirement index given in equation (12), and $f$ is the normal density function. $\hat{J}$ equals the coefficient estimates in Table 3 multiplied by their respective variables. Let $z$ denote any variable and $\hat{b}_{Z}$, its coefficient estimate, then the change in the retirement probability with respect to $Z$ is given by:

$$
\frac{\partial \hat{P}(D R=1)}{\partial z}=f(\hat{J}) \hat{b}_{z}
$$

where use is made of the fact that $f(-Z)=f(Z)$.

Equation (14) shows that the effect of one variable on the probability of retirement depends on its coefficient estimate and on the values of all other variables because of the presence of $\hat{J}$ in the argument of $f$. In order to calculate effects of variables, $\hat{J}$ was set equal to its value at the mean value of all variables (see Table 2), except that RACE was set equal to 1 and RURAL, 0 . The derivative of the retirement probability with respect to a variable was then computed according to equation (14). These estimated derivatives were multiplied by changes in the social security and wage variables and other selected 
variables to find the effect of these changes on the probability of retirement. These results are presented in Table 4.

Table 4 shows that, based on the estimated retirement models in Table 3, a $\$ 10,000$ increase in SSW raises the probability of retirement by .103 for 62 - 64 year olds and .108 for 65 - 70 year olds. This result assumes that the current benefit remains the same. Such an increase in SSW could be achieved through an increase in the present value of future benefits. Also, an increase in SSW has the same effect as a decrease in the present value of payroll taxes. This follows as an empirical result because the coefficient estimates for SSW and PVTAX are opposite in sign. Thus the main point to draw from the effect of an increase in SSW is that it measures the effect of a corresponding increase in lifetime income obtained through social security.

An increase in current benefits of $\$ 500$ has a substitution effect that raises the probability of retirement by .049 for $62-64$ year olds and . 149 for 65 - 70 year olds. In this case SSW is held constant. This could be achieved by increasing current benefits at the expense of future benefits. It is interesting to consider just the opposite, i.e. decreasing current benefits while keeping SSW constant. A $\$ 500$ reduction in current benefits would reduce retirement probabilities by the magnitudes just given for a benefit increase of the same amount. A decrease in current benefits that holds SSW constant is, by definition, actuarially fair. Such an actuarially fair reduction in current benefits would not result in lower benefit payments in total from social security to the individual (since SSW is constant). However, it would increase revenue for the system because people work more years, i.e. postpone retirement, and pay more taxes into the system. 
TABLE 4

ESTIMATED EFFECTS OF CHANGES IN VARIABLES

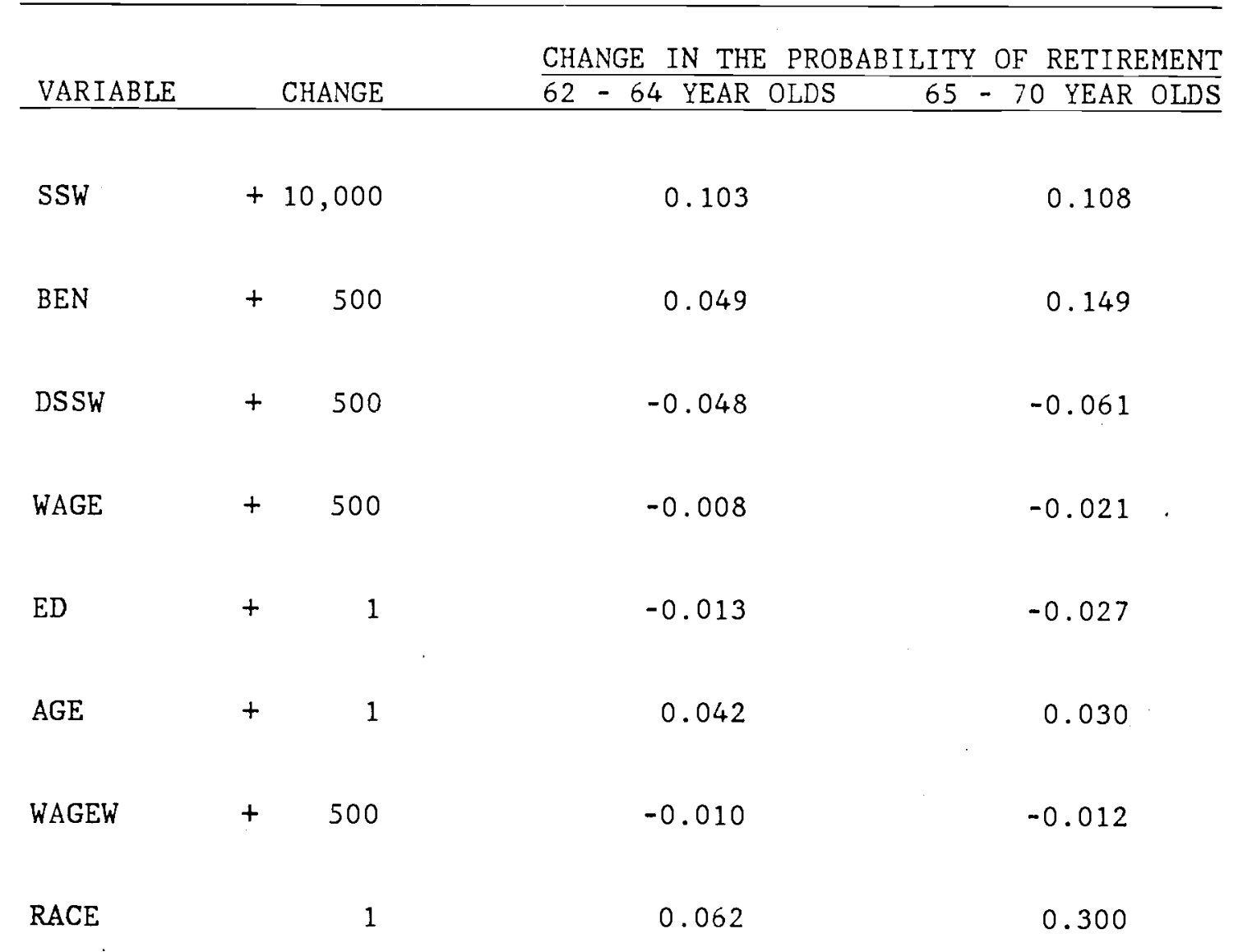


DSSW was shown in Table 3 to have a significant negative effect on the probability of retirement. This result provides empirical support for the point raised by Blinder, Gordon, and Wise (1980) that social secuity law, in particular the calculation of benefits from earnings, provides a work incentive. Table 4 shows that when DSSW goes up by $\$ 500$ the retirement probability decreases by .048 for $62-64$ year olds and .061 for 65 - 70 year olds. Whether the change is an increase in DSSW or a decrease in current benefits holding SSW constant as before, the idea is the same: retirement is postponed when future benefits can be raised by foregoing current benefits.

As discussed when $K$ was defined, the effect of the wage variable is not given in the coefficient of WAGE alone. Recall that $\mathrm{K}=1680 * 2080 /$ WAGE. As a result the wage effect is determined by both the coefficient of WAGE and the coefficient of $K$. To be precise:

$$
\frac{\partial \hat{\mathrm{P}}(\mathrm{DR}=1)}{\partial \text { WAGE }}=\left(\hat{\mathrm{b}}_{\text {WAGE }}-\hat{\mathrm{b}}_{K} \frac{1680 * 2080}{(\text { WAGE })^{2}}\right) f(\hat{J})
$$

where $\hat{b}_{W A G E}$ and $\hat{b}_{K}$ are the coefficient estimates for WAGE and $k$ in Table 3. Given the magnitude of these coefficient estimates and the fact that the minimum value of WAGE is $\$ 2000$, the estimated derivative of the retirement probability with respect to WAGE is always negative. Note that this derivative depends on the level of WAGE. This derivative was calculated at the mean value of WAGE in both age groups. Based on 
this derivative, Table 4 shows that a $\$ 500$ increase in an individual's annual wage decreases the probability of retirement by .008 for $62-64$ year olds and .021 for 65 - 70 year olds. The nonlinear wage effect yields the expected result that individuals with higher wages are less likely to retire.

Having $\mathrm{K}$ in the model to pick up any nonlinear effect of the wage variable is important. An argument can be made that the benefit variable is really just measuring a nonlinear wage effect that is being transmitted through the benefit formula. A person's benefit is, in part, a nonlinear transformation of his wage. However, the presence of $\mathrm{K}$ alleviates the problem posed by this argument.

The estimated effects of schooling conform with Mincer's (1974) hypothesis about the relationship between schooling and retirement. Individuals who obtain more schooling are expected to retire later. In the estimated models the coefficient estimates for schooling (ED) are significantly negative. A one year increase in the number of years of schooling lowers the probability of retirement by .103 for $62-64$ year olds and .027 for 65 - 70 year olds. The estimated effect of the wife's schooling is small and insignificant in both age groups.

Increases in age have the expected positive effect on retirement. An increase in age of one year raises the probability of retirement by .042 for 62 - 64 year olds and .030 for 65 - 70 year olds. Increases in the wife's age raise the probability of the husband's retirement as we11. The coefficient estimates for wife's age (AGEW) are smaller. The effect of the wife's age relative to that of the husband's is one-third for 62 - 64 year olds and one-eighth for 65 - 70 year olds. 
The effect of the wife's wage (WAGEW) on her husband's retirement is an interesting result. The highly significant negative coefficient estimates for WAGEW show that higher wages for a wife decrease the probability of her husband's retirement. A $\$ 500$ increase in the wife's wage reduces the husband's retirement probability by .010 for $62-64$ year olds and .012 for 65 - 70 year olds. This implies that husband's and wife's time are complements in household utility.

The race variable indicates that whites have a higher retirement probability. The coefficient estimate for RACE for 65 - 70 year olds is larger in magnitude and more precisely measured than for 62 - 64 year olds. These estimates imply that the retirement probability for whites, holding all the other variables constant, is higher than that for blacks by .062 for $62-64$ year olds and .300 for $65-70$ year olds.

The negative coefficient estimates for the variable RURAL indicate that retirement rates are lower for individuals who reside in a rural area. These coefficient estimates are not precisely measured though.

Both capital income (KINC) and the present value of earnings (PVE) were expected to have positive coefficient estimates in the model. The reason is that when a person's financial accumulation is larger it is possible to spend more time on leisure in later years, i.e. to retire early. For 62 - 64 year olds the coefficient estimates for KINC and PVE 
have the expected positive sign. However, the coefficient estimates for 65 - 70 year olds are opposite to what was expected. Since it was not possible to measure capital income and the present value of earnings precisely in the Exact Match dataset, problems in measuring KINC and PVE may be responsible for the unexpected coefficient estimates in the 65 70 year old age group. These variables were not important for the general purpose of this study. Also they did not have much effect on the results obtained for the other variables that were the focus of study. For these reasons KINC and PVE do not receive much attention in the empirical results.

\section{Summary and Conclusion}

The results of this study and their implications will be summarized briefly. In the framework of the life-cycle model social security was shown to have a potential lifetime income effect and two substitution effects on retirement. A retirement model was defined by expanding the standard labor force participation model to include life-cycle variables that would measure these potential effects of social security. The definition of nonparticipation implements the definition of retirement that is implicit in the rules for receiving full social security benefits. The retirement model was estimated using the 1973 Exact Match file, a dataset well suited for this study.

Retirement models were estimated for $62-64$ and $65-70$ year olds separately. The results showed that an increase in lifetime income 
obtained through social security raised the probability of retirement in both age groups. This increase could be achieved either through an increase in social security wealth or a decrease in the present value of payroll taxes. A clear implication of this result is that if the system were structured so that social security wealth equals the present value of payroll taxes there would be no lifetime income effect on retirement. Under such an actuarially fair system retirement rates would have been lower in past years because social security raised lifetime incomes of individuals reaching retirement age to date.

The results showed that social security's two substitution effects work in opposite directions on the decision to retire. Larger current benefits increase the probability of retirement. A larger gain in the value of future benefits obtained through earnings reduces the retirement probability. Given that the magnitude of the coefficient estimate for current benefits equals that for the earnings-induced increase in the value of future benefits for 62 - 64 year olds, social security's two substitution effects cancel in this age group. The estimated lifetime income effect implies that social security's net effect is to induce retirement for $62-64$ year olds.

The estimated effect of current benefits exceeds that of the earningsinduced increase in future benefits for 65 - 70 year olds. A plausible implication of this result is that individuals in the older age group discount future benefits at a rate higher than the one percent real rate used for both age groups. Consequently, both social security's income and substitution effects induce retirement in this age group. 
It is important to note that if social security were actuarially fair, social security's two substitution effects would cancel by the very nature of what it means for the system to be actuarially fair. In other words, social security would have no substitution effect by its very structure. As mentioned, it also would not change lifetime income. Thus, an actuarially fair social security system would have no economic effects on individual retirement decisions.

The results of this study have some interesting implications for retirement behavior in the future. As mentioned, most people reaching retirement age to date have experienced gains in lifetime income through social security. Such gains were made possible for a variety of reasons. ${ }^{17}$ However, social security has reached a point where such gains are no longer going to occur. Workers reaching retirement age in the next several years will be gaining little in lifetime income or breaking even. Several studies (see note 5 ) have shown that younger cohorts in the population can expect losses in lifetime income. Based on this reversal of social security's effect on lifetime income, it is possible to project a reversal in retirement rates in the future. Retirement rates can be expected to level off and go down.

17 Some workers did not pay taxes in the early years of their working career because the system had not yet begun. Even after the system started some workers were not covered until later. When a worker began to pay into the system the payroll tax rate and covered earnings level were low. Also, as the system grew because of growth in the population and extension of coverage to more workers, it was possible to raise benefits with little or no increase in taxes. For these reasons workers reached retirement age with a large increase in lifetime income from social security that could be realized by retiring. 
The main result of this study is the empirical evidence that social security affects the decision to retire. In a companion study (Pellechio, 1981b) social security's effect on how much people work even when they decide not to retire fully is examined. Bringing the social security earnings test into the analysis is an important factor in this study. These studies and future research with other data should contribute to the economics of retirement. 


\section{BIBLIOGRAPHY}

Aziz, Faye; Beth Kilss; and Frederick Scheuren. 1973 Current Populations Survey -- Administrative Record Exact Match File Codebook, Part I. Studies from Interagency Data Linkages, Report No. 8. U.S. Department of Health, Education, and Welfare. Social Security Administration. Office of Research and Statistics, 1978.

Ball, Robert M. Social Security. New York: Columbia University Press, 1978 .

Barro, Robert J. "Are Government Bonds Net Wealth?" Journal of Political Economy, Vol. 82, No. 6, November/December 1974, pp. 1095-1117.

Bayo, Francisco R.; William D. Ritchie; and Joseph F. Faber. "LongRange Cost Estimates for Old-Age, Survivors and Disability Insurance System, 1978." Actuarial Study No. 78, Office of the Actuary, Social Security Administration.

Blinder, Alan S.; Roger H. Gordon; and Donald E. Wise. "Reconsidering the Work Disincentive Effects of Social Security." National Bureau of Economic Research, Working Paper No. 562, October 1980.

Blinder, Alan S. and Yoram Weiss. "Human Capital and Labor Supply: A Synthesis." Journal of Political Economy, Vol. 84, No. 3, June 1976, pp. 449-472.

Board of Trustees, Federal 0ld-Age and Survivors Insurance and Disability Insurance Trust Funds. 1980 Annual Report. Committee on Ways and Means, U.S. Government Printing Office, 1980.

Boskin, Michael J. "Social Security and Retirement Decisions." Economic Inquiry, Vol. 15, No. 1, January 1977, pp. 1-25.

Bulow, Jeremy I. "Early Retirement Pension Benefits." National Bureau of Economic Research, Working Paper No. 654, April 1981. 
Campbel1, Colin D. and Rosemary G. Campbell. "Conflicting Views on the Effect of Old-Age and Survivors Insurance on Retirement." Economic
Inquiry, September 1976.

Clark, Robert L.; Thomas Johnson; and Daniel A. Sumner. "Labor Supply of the Elderly in a Family Context." North Carolina State University, March 1981.

Crawford, Vincent P. and David M. Lilien. "Social Security and the Retirement Decision." Quarterly Journal of Economics. August or
November, 1981.

Diamond, Peter and J.A. Mirrlees. "A Model of Social Insurance with Variable Retirement." Journal of Public Economics, 1978.

Esposito, Louis and Michael Packard. "Social Security and the Labor Supply of Aged Men: Evidence from the U.S. Time Series." U.S. Department of Health and Human Services. Social Security Administration. Office of Policy. Office of Research and Statistics Working Paper Series Number 21, December 1980.

Feldstein, Martin S. "Social Security and the Distribution of Wealth." Journal of the American Statistical Association, December 1976a.

Feldstein, Martin S. "Social Security and Saving: The Extended Life 6ycle Theory." No. 1, May $1976 \mathrm{~b}, \mathrm{pp} \cdot \frac{\mathrm{Aconomic}}{77-86 .}$ Review Papers and Proceedings, Vol.

Ferrara, Peter J. Social Security: The Inherent Contradiction. San Francisco: Cato Institute, 1980.

Fox, Alan. "Appendix F: Methodology for Chapter 14." In Reaching Retirement Age: Findings from a Survey of Newly Entitled Workers 1968-70. U.S. Department of Health, Education, and Welfare. Social Security Administration. Office of Research and Statistics. Research Report No. 47. Washington, D.C.: 'Government Printing
Office, 1976 .

Gronau, Reuben. "The Effect of Children on the Housewife's Value of Time." Journal of Political Economy, Vol. 81, No. 2, Part 2, March/April 1973, pp. S168-S199. 
Gronau, Reuben. "Leisure, Home Production, and Work - the Theory of the Allocation of Time Revisited." Journal of Political Economy,

December 1977.

Ha11, Robert E. "Effects of the Experimental Negative Income Tax on Labor Supply." In Pechman and Timpane, eds., Work Incentives and Income Guarantees. Washington, D.C.: The Brookings Institution, 1975, pp. 115-147.

Hanoch, Giora. "A Multivariate Model of Labor Supply: Methodology for Estimation." The Rand Corporation, R-1869-HEW, September 1976.

Heckman, James. "Shadow Prices, Market Wages, and Labor Supply." Econometrica, Vol. 42, No. 4, July 1974, pp. 679-694.

Heckman, James." "A Life-Cycle Model of Earnings, Learning, and Consumption." Journal of Political Economy, Vol. 84, No. 4, Part 2, August 1976, pp. S11-S44.

Hu, Sheng Cheng. "Social Security, the Supply of Labor, and Capital Accumulation." American Economic Review. June 1979.

Kotlikoff, Laurence J. "Testing the Theory of Social Security and Life Cycle Accumulation." American Economic Review. June 1979.

Kurz, Mordecai. "Optimal Retirement Age." Stanford University, Institute for Mathematical Studies in the Social Sciences, Economics Series Technical Report No. 336, May 1981.

Leimer, Dean R. and Peter A. Petri. "Cohort-Specific Effects of Social Security Policy." U.S. Department of Health and Human Services. Social Security Administration. Office of Policy. Office of Research and Statistics Working Paper Series Number 20, December 1980.

Mincer, Jacob. Schooling, Experience, and Earnings. National Bureau of Economic Research. New York: Columbia University Press, 1974.

Mitchell, Olivia S. and Gary S. Fields. "The Effect of Pensions on Retirement: A Review Essay." Cornell University, February 1981. 
Myers, R.J. "Earnings Test Under Old-Age Survivors and Disability Insurance: Basic Background and Experience." Social Security
Bulletin, 1964.

Nichols, Orlo R. and Richard G. Schreitmueller. "Some Comparisons of the Value of a Worker's Social Security Taxes and Benefits." Social Security Administration, Actuarial Note Number 95, April 1978.

Pellechio, Anthony J. "Social Security Financing and Retirement Behavior." American Economic Review, May 1979a.

Pellechio, Anthony J. "The Estimation of Labor Supply Over Kinked Budget Constraints: Some New Econometric Methodology." National Bureau of Economic Research, Working Paper No. 387, August 1979b.

Pellechio, Anthony J. "Individual Gains and Losses from Social Security: Calculations in 1981 According to Social Security Law and an Agenda for Reform." February, 1981 .

Pellechio, Anthony J. "The Social Security Earnings Test and Retirement Behavior." June 1981b.

Petri, Peter A. (Chairman). "Perspectives on Long-Range Social Security Policy: Report of a Social Security Administration Taskforce on Long-Range Policy Issues." August, 1980.

Samuelson, Paul A. "Optimum Social Security in a Life-Cycle Growth Model." International Economic Review, October 1975.

Sheshinski, Eytan. "A Model of Social Security and Retirement Decisions." Journal of Public Economics, December 1978.

U.S. Department of Commerce. Bureau of the Census. Projections of the Population of the United States: 1977 to 2050. Series P-25, No.

U.S. Department of Health and Human Services. Social Security Administration. Social Security Bulletin: Annual Statisitical Supplement, $1977-\overline{79}$. 